\title{
Dietary fibre analysis
}

\author{
Barry V. McCleary \\ Megazyme International Ireland Limited, Bray Business Park, Bray, County Wicklow, Republic of Ireland
}

\begin{abstract}
The 'gold standard' method for the measurement of total dietary fibre is that of the Association of Official Analytical Chemists (2000; method 985.29). This procedure has been modified to allow measurement of soluble and insoluble dietary fibre, and buffers employed have been improved. However, the recognition of the fact that non-digestible oligosaccharides and resistant starch also behave physiologically as dietary fibre has necessitated a re-examination of the definition of dietary fibre, and in turn, a re-evaluation of the dietary fibre methods of the Association of Official Analytical Chemists. With this realisation, the American Association of Cereal Chemists appointed a scientific review committee and charged it with the task of reviewing and, if necessary, updating the definition of dietary fibre. It organised various workshops and accepted comments from interested parties worldwide through an interactive website. More recently, the (US) Food and Nutrition Board of the Institute of Health, National Academy of Sciences, under the oversight of the Standing Committee on the Scientific Evaluation of Dietary Reference Intakes, assembled a panel to develop a proposed definition(s) of dietary fibre. Various elements of these definitions were in agreement, but not all. What was clear from both reviews is that there is an immediate need to re-evaluate the methods that are used for dietary fibre measurement and to make appropriate changes where required, and to find new methods to fill gaps. In this presentation, the 'state of the art' in measurement of total dietary fibre and dietary fibre components will be described and discussed, together with suggestions for future research.
\end{abstract}

Total dietary fibre: Resistant starch: Non-digestible oligosaccharides: Non-starch polysaccharides

\section{Historical developments}

Henneberg \& Stohmann (1860) developed the proximate analysis system for feeds. The carbohydrate content of a sample was determined by difference. Methods were available for the measurement of water, $\mathrm{N}$ (converted to protein by a standard factor), lipids extractable in an organic solvent and mineral matter (i.e. ash). When the proximate analysis system was applied in studies of ruminant physiology, it became apparent that the feed value of carbohydrates measured by difference was not constant. An insoluble fibrous fraction could be identified that was not digested. This observation led to the development of the crude fibre method using successive acid and alkaline digestion to isolate this indigestible fraction. The detergent methods introduced by Van Soest $(1963 a, b)$ and Van Soest \& Wine (1967) led to considerable improvement in the prediction of the feed value, compared with the crude fibre method.

The crude fibre method was brought into human nutrition at the turn of the 19 th century. McCance \&
Lawrence (1929) introduced the differentiation between 'available' and 'unavailable' carbohydrates. This step was a milestone in our understanding of the nutritional importance of different food carbohydrates. The main objective was to differentiate those carbohydrates that affected the blood glucose levels, i.e. those 'available' for digestion and absorption in the small intestine. Widdowson \& McCance (1935) developed methods for analysing reducing sugars, sucrose and starch in foods as a measure of the available carbohydrates. Unavailable carbohydrates were determined as the insoluble residue, corrected for protein and ash. More recent development in dietary fibre methodology has adopted two general approaches (Asp, 2000), enzymic-gravimetric methods and enzymicchemical methods. Williams \& Olmstedt (1935) developed a more physiological method for estimating indigestible material than the crude fibre method. This method simulated digestion by incubating the food sample with enzymes. Their work was the basis for enzymicgravimetric methods developed later by Thomas (1972) and Hellendoorn et al. (1975). 


\section{Enzymic-gravimetric methods}

The main steps in the current gravimetric dietary fibre methods (for example, see Association of Official Analytical Chemists, 2000; method 985.29) include enzymic treatments for starch and protein removal, precipitation of soluble dietary fibre components by aqueous ethanol, isolation and weighing of the dietary fibre residue, and correction for protein and ash in the residue (Asp \& Johansson, 1984; Asp et al. 1992; Cho et al. 1997).

Schaller (1976) introduced amylase treatment into the neutral-detergent fibre method of Van Soest \& Wine (1967), in order to resolve problems experienced when the method was applied to starchy foods or ingredients in which starch was incompletely solubilised (American Association of Cereal Chemists, 2000; method 32-20 for insoluble dietary fibre). Mongeau \& Brassard $(1986,1990)$ added the determination of a soluble fibre fraction to a modified neutraldetergent fibre procedure. This further modification gave a rapid gravimetric method that showed excellent precision but had limitations in incomplete removal of starch and/or protein in some kinds of samples.

The first gravimetric procedures that measured both the insoluble and soluble components of dietary fibre were developed independently by Furda (1977, 1981), Schweizer \& Würsch $(1979,1981)$ and Asp \& Johansson (1981). These authors, together with DeVries, Prosky and Harland, designed the first version of the enzymic-gravimetric method of the Association of Official Analytical Chemists (2000; method (985.29). This procedure was adopted for final action in 1986 (Prosky et al. 1984, 1985). The method was later adapted for insoluble and soluble fibre, and then further simplified using 4-morpholine-ethanesulfonic acidTRIS buffer (Lee et al. 1992; Association of Official Analytical Chemists, 2000; method 991.43).

\section{Enzymic-chemical methods}

The enzymic removal of starch is also an essential first step in the enzymic-chemical methods. Precipitation with $80 \%$ $(\mathrm{v} / \mathrm{v})$ ethanol is used to separate the soluble dietary fibre polysaccharides from low-molecular-weight sugars and starch hydrolysis products.

Southgate $(1969 a, b, 1981)$ developed a procedure following the principles of Widdowson \& McCance (1935), so that a complete carbohydrate analysis of sugars, starches, non-cellulose polysaccharides, cellulose and lignin could be carried out sequentially on the same sample. Problems were experienced in the complete removal of starch and in the semi-specific colorimetric reactions for hexoses, pentoses and uronic acids. Schweizer \& Würsch (1979) published a GLC method for the characterisation of gravimetricallydetermined soluble and insoluble dietary fibre residues. In the same year, Theander \& Åman (1979) published the first version of the Uppsala methodology using GLC for the determination and characterisation of soluble and insoluble fractions of dietary fibre; a Klason lignin determination was included. Englyst (Southgate et al. 1978; Englyst, 1981; Englyst \& Cummings, 1984) developed a GLC-based method as an extension of the method of Southgate (1969b). Over the years this method has undergone many changes related to the enzymes used and the procedures used to measure monosaccharides and uronic acids (Englyst \& Hudson, 1987; Quigley \& Englyst 1992).

In the method of Theander \& Åman (Theander et al. 1990) starch is gelatinised and hydrolysed by incubation with thermostable $\alpha$-amylase in a boiling water-bath, then soluble-fibre polysaccharides are precipitated in $80 \%(\mathrm{v} / \mathrm{v})$ ethanol, and the dietary fibre residue containing soluble as well as insoluble fibre is obtained by centrifugation. The neutral sugar contents of the hydrolysed polysaccharides are determined by GLC, and uronic acids are determined colorimetrically.

\section{The current situation}

Over the past decade, the importance of non-digestible oligosaccharides (NDO) and resistant starch as dietary fibre components (based on their physiological behaviour) has been recognised. This issue, together with the recognised value of 'intrinsic intact dietary fibre from plant tissue', and questions concerning the importance of separatelydetermined 'soluble' and 'insoluble' dietary fibre components, has led to the realisation that the definition of dietary fibre needed to be revisited. This challenge was taken up initially by the American Association of Cereal Chemists (Anonymous, 2001a), and then by the (US) Food and Nutrition Board of the Institute of Health (Anonymous, $2001 b$ ), under the oversight of the Standing Committee on the Scientific Evaluation of Dietary Reference Intakes. It was realised that the most-widely-accepted physiologicallybased definitions have generally been accurate in defining dietary fibre in foods; however, scientists and regulators have tended to rely on analytical procedures as the definitional basis. Meanwhile, the Food and Nutrition Board Panel concluded that the current situation regarding labelling and defining dietary fibre in most countries, including the USA, was arbitrary, due to the reliance on analytical methodology as opposed to an accurate definition that includes its role in health. Two refined definitions of dietary fibre resulted from these studies.

\begin{abstract}
American Association of Cereal Chemists (Anonymous, 2001a) definition:

'Dietary fibre is the edible parts of plants or analogous carbohydrates that are resistant to digestion and absorption in the human small intestine with complete or partial fermentation in the large intestine. Dietary fibre includes polysaccharides, oligosaccharides, lignin and associated plant substances. Dietary fibres promote beneficial physiological effects including laxation, and/or blood cholesterol attenuation, and/or blood glucose attenuation.'
\end{abstract}

Food and Nutrition Board of the US Institute of Health (Anonymous, 2001b) definition:

'Dietary Fiber consists of nondigestible carbohydrates and lignin that are intrinsic and intact in plants. Added Fiber consists of isolated, nondigestible carbohydrates that have beneficial physiological effects in humans. Total Fiber is the sum of Dietary Fiber and Added Fiber.'

Both these definitions are based on physiological concepts, but they do encompass differences that will 
introduce interesting or impossible analytical challenges. For example, to enforce the second definition there would be a need to be able to separately analyse for 'dietary fibre' and 'added fibre'. This analysis is possible before the components are mixed, but once mixed the distinction of the source of the component will be virtually impossible, e.g. measuring pectin in a plant-based food product that already contains this polysaccharide as part of the intact plant tissue and as an added fibre.

Clearly, the whole area of definition and measurement of dietary fibre is currently in a state of flux and rapid evolution. This situation does not mean that up to this point in time analytical methodology rather than the physiological importance of dietary fibre has preoccupied scientists and regulators. In fact, the opposite was the case. Before blindly discarding earlier achievements and rushing forward, we should reflect on a comment by Asp (2001): 'The definition and analysis of dietary fibre are intimately related. Analysis methods have to be developed in accordance with the conceptual definitions, but in practice, compromises must be accepted due to constraints of cost and time. All types of dietary components can be separated at different levels of complexity and determined separately for research purposes, though short-hand methods are needed for labelling and control purposes.' From this statement, it is clear that Asp, one of the major contributors to our knowledge of dietary fibre, and a important contributor to dietary fibre analytical methodology, is not only well aware of what can be measured, but also of what is likely to be achievable for labelling and control purposes.

\section{Moving forward}

It is clear that two types of dietary fibre methodology are required: enzymic gravimetric for food labelling and control purposes; enzymic chemical for research purposes. These methods must yield similar dietary fibre results. Certainly, the combination of Association of Official Analytical Chemists (2000) methods 985.29 and 991.43 (total dietary fibre) and the Uppsala enzymic-chemical method (Association of Official Analytical Chemists, 2000; method 994.13) form the basis of filling these requirements. This basic solution is achieved, of course on the condition that the enzymes used in the methods $(\alpha$-amylase, protease and amyloglucosidase) are of the required activity and purity (McCleary, 1999, 2000). However, modifications must be made to account for NDO that are removed in the alcohol wash step, inulin and fructo-oligosaccharides that are partially removed in the alcohol wash step and resistant starch, which is partially degraded and thus incompletely analysed by the Official Analytical Chemists methods. Also, the physiological relevance of the analytical entities 'soluble' and 'insoluble' dietary fibre needs to be addressed. Some of these issues will be discussed later.

\section{Non-digestible oligosaccharides}

A wide variety of NDO either occur in nature, or have been produced through acid or enzymic hydrolysis or transglycosylation. Many of these NDO find application in foods in Japan (Meyer \& Tungland, 2001), and an increasing number are being accepted worldwide. Of these NDO, those most commonly used are fructo-oligosaccharides, $\beta$-galacto-oligosaccharides, polydextrose, fibersol 2 and $\alpha$-galacto-oligosaccharides (raffinose and stachyose). Specific methods have been developed for each of these NDO, and have gained AOAC acceptance following interlaboratory evaluation.

Fructo-oligosaccharides and inulin. Inulin and fructooligosaccharides are extracted from chicory and Jerusalem artichoke on an industrial scale. High levels are also found in onion and the leaf tissue of many grasses. Naturally occurring fructans are non-reducing, as also are the neosugars, which are produced from sucrose by transglycosylation (Hirayama \& Hidaka, 1993). Fructo-oligosaccharides are also produced through acid or enzymic hydrolysis of inulin. Two fructan assay methods have been subjected to inter-laboratory evaluation under the auspices of Association of Official Analytical Chemists (AOAC) International. AOAC method 997.08 (Hoebregs, 1997) employs enzymic hydrolysis together with high-performance anion-exchange chromatography (HPAEC) with pulsed amperometric detection. Extracts from the sample are subjected to HPAEC with pulsed amperometric detection directly after extraction, and following treatment with amyloglucosidase or amyloglucosidase plus crude fructanase. From the chromatographic patterns the levels of sucrose and fructose in the untreated extract, the levels of fructose, glucose and sucrose in the amyloglucosidase-treated extract and the levels of fructose and glucose in the amyloglucosidase plus fructanase-treated extract are determined. From these values it is possible to calculate fructan content by subtracting free glucose, fructose and sucrose in the sample and glucose from starch. The method is applicable to inulin and non-reducing and reducing fructo-oligosaccharides. The major limitation is the cost of the equipment required and the technical expertise needed to keep it running.

The second method to receive AOAC approval (method 999.03) is based totally on the use of specific enzymes (McCleary \& Blakeney, 1999; McCleary et al. 2000). The procedure employs a specific sucrase enzyme to hydrolyse sucrose to glucose plus fructose, and a mixture of $\beta$-amylase, pullulanase and maltase to hydrolyse starch to glucose. These enzymes have no action on fructo-oligosaccharides. The hydrolysis mixture is then treated with sodium borohydride to reduce reducing sugars to sugar alcohols. On neutralisation a mixture of pure exo-inulinase and endoinulinase is added. The fructan and fructo-oligosaccharides are quantitatively hydrolysed to fructose and glucose, which is measured using the $p$-hydroxybenzoic acid hydrazide reducing sugar method. This method is applicable to inulin and non-reducing fructo-oligosaccharides (e.g. native oligosaccharides and neosugars) in any matrix. However, for highly-degraded (acid or enzymic) fructan, there is an underestimation. This is due to the fact that the reducing ends of the hydrolysed fructo-oligosaccharides are converted to sugar alcohols in the sodium borohydride reduction step, resulting in their non-measurement in the reducing sugar assay. An outline of this method is shown schematically in Fig. 1.

trans-Galacto-oligosaccharides. These NDO are produced by the transglycosylation action of $\beta$-galactosidase 
FRUCTAN + SUCROSE + STARCH

Sucrase $+\beta$-amylase + pullulanase + maltase

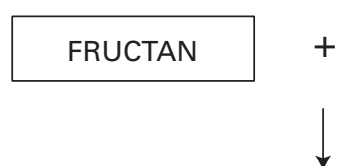

FRUCTOSE + GLUCOSE

Sodium borohydride and acetic acid

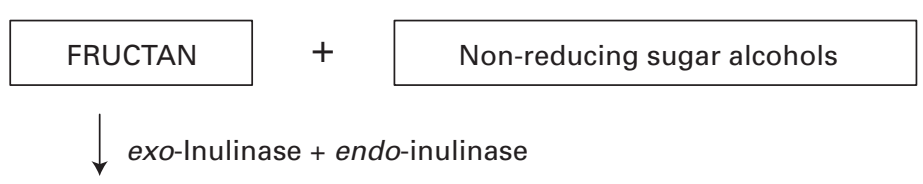

FRUCTOSE + GLUCOSE

PAHBAH reducing-sugar determination

FRUCTAN CONTENT

Fig. 1. Schematic representation of a procedure for the measurement of inulin and fructo-oligosaccharides; Association of Official Analytical Chemists method 999.03 (McCleary \& Blakeney, 1999; McCleary et al. 2000). PAHBAH, $p$-hydroxybenzoic acid hydrazide.

under certain incubation conditions. Analysis also involves the use of this enzyme (AOAC method 2001.02; De Slegte, 2002). The sample is extracted with hot phosphate buffer and analysed for free galactose and lactose by HPAEC. A separate aliquot of the extract is treated with $\beta$-galactosidase and analysed for galactose by HPAEC. Galacto-oligosaccharide content is determined by subtracting the galactose derived from the lactose, plus the free galactose in the material, from total galactose.

Polydextrose. In recent years, several methods have been developed for the measurement of polydextrose, and one of these has recently been accepted as an AOAC standard method (method 2000.11; Craig, 2001) following inter-laboratory evaluation. Polydextrose is prepared by vacuum thermal polymerisation of glucose, using sorbitol and an approved food acid as catalyst. Random polymerisation and branching yield various types of glycosidic bonds in the structure (1,6 bonds predominate). The average degree of polymerisation is 12 . Analysis involves extraction of the sample with hot water, followed by centrifugation and centrifugal ultrafiltration (to remove high-molecular-weight components). The extract is then treated with isoamylase and amyloglucosidase to depolymerise malto-saccharides, and with a pure fructanase mixture to hydrolyse fructo-oligosaccharides to monosaccharides. The solution is then analysed by HPAEC with pulsed amperometric detection.

Fibersol 2. Fibersol 2 is produced by a combination of heat and enzymic treatment of maize starch. In the first reaction maize starch is heated with a small amount of $\mathrm{HCl}$ under low moisture conditions. In the second reaction the solution obtained previously is hydrolysed with $\alpha$-amylase. The material is then purified and analysed to ensure that the dextrose equivalent is below 20. The presence of fibersol 2 in food materials is determined by a modification of the
Association of Official Analytical Chemists (2000) method 985.29. The sample is analysed for insoluble dietary fibre and soluble high-molecular-weight fibre by this procedure, and the ethanol solution and washings are combined, filtered, evaporated, desalted and analysed by HPLC (AOAC method 2001.03; Gordon \& Okuma, 2002). The oligosaccharides fall into the category of low-molecularweight soluble dietary fibre.

\section{Resistant starch}

By definition, resistant starch is that portion of the starch that is not broken down by human enzymes in the small intestine. It enters the large intestine, where it is partially or wholly fermented. Resistant starch is now considered to be part of dietary fibre. Any method used to measure resistant starch must give values in-line with those obtained with ileostomy patients. In recent years several methods for the measurement of resistant starch have been developed, and some of these procedures have been subjected to limited inter-laboratory evaluation. Clearly, since no method has been generally adopted, there was a need to re-evaluate the available methods to determine which performed the best. Each of the most commonly used procedures (Englyst et al. 1992; Champ et al. 1999, 2001; Goni et al. 1996) has been evaluated in our laboratories. In the current study each step in the procedure was evaluated in detail, including: initial conditions of incubation with pancreatic $\alpha$-amylase ( $\mathrm{pH}$, time, stirring and shaking, level of added amyloglucosidase); method for terminating the reaction and recovering the resistant starch-containing pellet; procedures for redissolving the resistant starch; conditions for complete hydrolysis of the resistant starch and measurement of the released glucose. The method finally developed (McCleary $\&$ Monaghan, 2002) gave resistant starch values for a range 


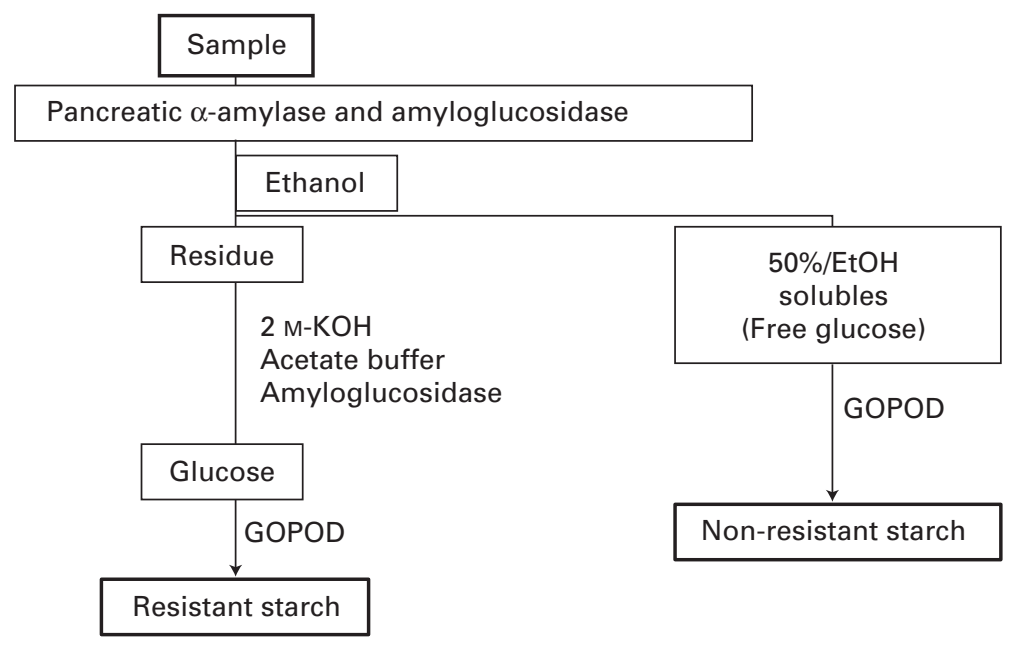

Fig. 2. Schematic representation of a procedure for the measurement of resistant starch; Association of Official Analytical Chemists method 2002.02 (McCleary \& Monaghan, 2002). GOPOD, glucose oxidase-peroxidase; EtOH, ethanol.

of samples in-line with those obtained with ileostomy patients (Champ et al. 2001). An outline of the procedure is shown in Fig. 2. The procedure has been subjected to interlaboratory evaluation under the auspices of AOAC International and the American Association of Cereal Chemists, and has gained 'First Status' approval by both associations (AOAC method 2002.02 (McCleary \& Monaghan, 2002); American Association of Cereal Chemists (unpublished results) method 32-40).

\section{Incorporation of fructan, resistant starch and non-digestible oligosaccharides values into total dietary fibre}

Clearly if fructan, resistant starch and NDO are specifically analysed, and the values are to be added to the value of total dietary fibre obtained by the Association of Official Analytical Chemists (2000) method 985.29 or the Association of Official Analytical Chemists (2000) method 991.43 then it must be ensured that none of the material is "counted twice'. In other words, if the individual component is to be analysed and added to total dietary fibre, then the sample must be treated to remove essentially all the component from the high-molecular-weight material measured in method 985.29. Since most of the NDO (except some of the fructo-oligosaccharides) are soluble in $80 \%(\mathrm{v} / \mathrm{v})$ ethanol, their removal is simple. Removal of fructo-oligosaccharides can be achieved by treatment of the sample with fructanase at the amyloglucosidase incubation step (Quemener et al. 1997). However, it is essential that the added fructanase is devoid of enzymes that will depolymerise other fibre components (e.g. pectin and $\beta$-glucan; McCleary, 1999).

Complete removal of resistant starch requires solubilisation of the starch before treatment of the sample with thermostable $\alpha$-amylase. This step can be achieved by either cooking the sample in dimethyl suphoxide or by stirring in cold $2 \mathrm{M}-\mathrm{KOH}$. The first approach is preferable because it causes minimum modification of other polysaccharides, and does not interfere with the alcohol precipitation step (BV McCleary, unpublished results). If $\mathrm{KOH}$ is employed, neutralisation (required for enzyme treatments) results in high levels of salt, and some of this salt precipitates on the addition of the ethanol (giving high and variable ash readings).

\section{Conclusions}

With the recognition of NDO, inulin and resistant starch as dietary fibres, appropriate methodology is being developed. The availability of methods for the specific measurement of particular NDO is useful, but may not be manageable for an analyst posed with the problem of analysing an unknown sample for total dietary fibre. Clearly, for labelling and control purposes there is a need for a universal method that will measure NDO as a group. Basically, the method would measure all oligosaccharides except malto-saccharides and sucrose. In our laboratory, we are currently evaluating several approaches to this analytical problem, including chromatographic procedures and combined chemical procedures. The main approach involves the use of a mixture of sucrase, pullulanase, $\beta$-amylase and maltase to hydrolyse sucrose and maltodextrins to monosaccharides. The oligosaccharides are then measured as a group either directly by HPLC, or (following sodium borohydride reduction of the reducing sugars to sugar alcohols) by the phenol- $\mathrm{H}_{2} \mathrm{SO}_{4}$ colorimetric method. The phenol- $\mathrm{H}_{2} \mathrm{SO}_{4}$ approach is based on the fact that sugar alcohols give no colour formation in this reaction. This latter approach is very simple, but it is limited by the fact that different sugars give varying colour responses; in particular fructose gives just 55-60 \% (BV McCleary, unpublished results) of the colour obtained with glucose (i.e. compare the measurement of fructo-oligosaccharides with polydextrose or fibersol 2). Also, the terminal reducing sugar in oligosaccharides is converted to a sugar alcohol in the sodium borohydride reduction step, resulting in a proportional underestimate of the levels of the oligosaccharides. At present, the HPLC approach to quantification appears most promising, but research is continuing in a number of areas. 


\section{References}

Anonymous (2001a) The definition of dietary fibre. Cereal Foods World 46, 112-126.

Anonymous (2001b) Dietary Reference Intakes; Proposed Definition of Dietary Fibre. Washington, DC: Food and Nutrition Board of the Institute of Health, National Academy of Science, National Academy Press.

Asp N-G (2001) Development of dietary fibre methodology. In Advanced Dietary Fibre Technology, pp. 77-88 [BV McCleary and L Prosky, editors]. Oxford: Blackwell Science Ltd.

Asp N-G \& Johansson C-G (1981) Techniques for measuring dietary fiber. In The Analysis of Dietary Fiber in Food, pp. 173-189 [WPT James and O Theander, editors]. New York: Marcel Dekker.

Asp N-G \& Johansson C-G (1984) Dietary fibre analysis. Nutrition Abstracts and Reviews 54, 735-752.

Asp N-G, Schweizer TF, Southgate DAT \& Theander O (1992) Dietary fibre analysis. In Dietary Fibre - A Component of Food. Nutritional Function in Health and Disease, pp. 57-102 [TF Schweizer and CA Edwards, editors]. London: Springer-Verlag.

American Association of Cereal Chemists (2000) Method 32-20 for insoluble dietary fibre

Association of Official Analytical Chemists (2000) Method 985.29 for dietary fibre

Association of Official Analytical Chemists (2000) Method 991.43 for soluble and insoluble dietary fibre

Association of Official Analytical Chemists (2000) Method 994.13; the Uppsala enzymic/chemical method

Champ M, Kozlowski F \& Lecannu G (2001) In Advanced Dietary Fibre Technology, pp. 106-119 [BV McCleary and L Prosky, editors]. Oxford: Blackwell Science Ltd.

Champ M, Marti L, Noah L \& Gratas M (1999) Analytical methods for resistant starch. In Complex Carbohydrates in Food, pp. 169-187 [SS Cho, L Prosky and M Dreher, editors]. New York: Marcel Dekker Inc.

Cho S, DeVries J \& Prosky L (1997) Dietary Fibre Analysis and Applications. Gaithesburg, MD: Association of Official Analytical Chemists International.

Craig AS (2001) Polydextrose: analysis and physiological benefits. In Advanced Dietary Fibre Technology, pp. 503-508 [BV McCleary and L Prosky, editors]. Oxford: Blackwell Science Ltd.

De Slegte J (2002) Determination of trans-galactooligosaccharides in selected food products by ion-exchange chromatography: collaborative study. Journal of the Association of Official Analytical Chemists 85, 417-423.

Englyst HN (1981) Determination of carbohydrates and its composition in plant materials. In The Analysis of Dietary Fiber in Food, pp. 173-189 [WPT James and O Theander, editors]. New York: Marcel Dekker.

Englyst HN \& Cummings JH (1984) Simplified method for the measurement of total non-starch polysaccharides by gas-liquid chromatography of constituent sugars as alditol acetates. Analyst 109, 937-942.

Englyst HN \& Hudson G (1987) Colorimetric method for routine measurement of dietary fibre as non-starch polysaccharides. A comparison with gas-liquid chromatography. Food Chemistry 24, 63-76.

Englyst HN, Kingman SM \& Cummings JH (1992) Classification and measurement of nutritionally important starch fractions. European Journal of Clinical Nutrition 46, S33-S39.

Furda I (1977) Fractionation and examination of biopolymers from dietary fiber. Cereal Foods World 22, 252-254.

Furda I (1981) Simultaneous analysis of soluble and insoluble dietary fiber. In The Analysis of Dietary Fiber in Food, pp. 163-172 [WPT James and O Theander, editors]. New York: Marcel Dekker.
Goni I, Garcia-Diz E, Manas E \& Saura-Calixto F (1996) Food Chemistry 56, 445-449.

Gordon DT \& Okuma K (2002) Determination of total dietary fibre in selected foods containing resistant maltodextrins by enzymatic-gravimetric method and liquid chromatography: collaborative study. Journal of the Association of Official Analytical Chemists 85, 435-444.

Hellendoorn EW, Noordhoff MG \& Slagman J (1975) Enzymatic determination of the indigestible residue (dietary fibre) content of human food. Journal of the Science of Food and Agriculture 26, 1461-1468.

Henneberg W \& Stohmann F (1860) Beiträge zur Begründung einer rationellen Fütterung der Wiederkäuer, vol. 1. Braunschweig, Germany.

Hirayama M \& Hidaka H (1993) Production and utilization of microbial fructans. In Science and Technology of Fructans, pp. 273-302 [M Suzuki and NJ Chatterton, editors]. Boca Raton, FL: CRC Press.

Hoebregs H (1997) Fructans in food and food products, ionexchange-chromatographic method: Collaborative study. Journal of the Association of Official Analytical Chemists 80, 1029-1037.

Lee S, Prosky L \& DeVries J (1992) Determination of total, soluble, and insoluble dietary fiber in foods: Enzymatic-gravimetric method, MES-TRIS buffer: Collaborative study. Journal of the Association of Official Analytical Chemists 75, 395-416.

McCance RA \& Lawrence RD (1929) The Carbohydrate Content of Foods. Medical Research Council Special Report Series no. 135. London: H.M. Stationery Office.

McCleary BV (1999) Enzyme purity and activity in fibre determinations. Cereal Foods World 44, 590-596.

McCleary BV (2000) The importance of enzyme purity and activity in the measurement of total dietary fibre and dietary fibre components. Journal of the Association of Official Analytical Chemists 83, 997-1005.

McCleary BV \& Blakeney AB (1999) Measurement of inulin and oligofructan. Cereal Foods World 44, 398-406.

McCleary BV \& Monaghan DA (2002) Measurement of resistant starch. Journal of the Association of Official Analytical Chemists 85, 665-675.

McCleary BV, Murphy A \& Mugford DC (2000) Measurement of oligofructan and fructan polysaccharides in foodstuffs by an enzymic/spectrophotometric method: Collaborative study. Journal of the Association of Official Analytical Chemists 83, 356-364.

Meyer D \& Tungland B (2001) Non-digestible oligosaccharides and polysaccharides: their physiological effects and health implications. In Advanced Dietary Fibre Technology, pp. 455-470 [BV McCleary and L Prosky, editors]. Oxford: Blackwell Science Ltd.

Mongeau R \& Brassard R (1986) A rapid method for the determination of soluble and insoluble dietary fiber: Comparison with AOAC total dietary fiber procedure and Englyst's method. Journal of Food Science 51, 1333-1336.

Mongeau R \& Brassard R (1990) Determination of insoluble, soluble, and total dietary fiber: Collaborative study of rapid gravimetric method. Cereal Foods World 35, 319-325.

Prosky L, Asp NG, Furda I, DeVries JW, Schweizer TF \& Harland BF (1984) Determination of total dietary fiber in foods, food products, and total diets: Interlaboratory study. Journal of the Association of Official Analytical Chemists 67, 1044-1052.

Prosky L, Asp NG, Furda I, DeVries JW, Schweizer TF \& Harland BF (1985) Determination of total dietary fiber in foods and food products: collaborative study. Journal of the Association of Official Analytical Chemists 68, 677-679.

Quemener B, Thibault J-F \& Coussement P (1997) Integration of inulin determination in the AOAC method for measurement of 
total dietary fibre. International Journal of Biological Macromolecules 21, 175-178.

Quigley ME \& Englyst HN (1992) Determination of neutral sugars and hexosamines by high-performance liquid chromatography with pulsed amperometric detection. Analyst 117, $1715-1718$.

Schaller DA (1976) Analysis of dietary fiber. Food Production and Development 11, 70-72.

Schweizer TF \& Würsch P (1979) Analysis of dietary fibre. Journal of the Science of Food and Agriculture 30, 613-619.

Schweizer TF \& Würsch P (1981) Analysis of dietary fiber. In The Analysis of Dietary Fiber in Food, pp. 203-216 [WPT James and O Theander, editors]. New York: Marcel Dekker.

Southgate DAT (1969a) Determination of carbohydrates in food. I. Available carbohydrates. Journal of the Science of Food and Agriculture 20, 326-330.

Southgate DAT (1969b) Determination of carbohydrates in food. II. Unavailable carbohydrates. Journal of the Science of Food and Agriculture 20, 331-335.

Southgate DAT (1981) Use of the Southgate method for unavailable carbohydrates in the measurement of dietary fiber. In The Analysis of Dietary Fiber in Food, pp. 1-19 [WPT James and O Theander, editors]. New York: Marcel Dekker.

Southgate DAT, Hudson GJ \& Englyst HN (1978) The analysis of dietary fibre: the choices for the analyst. Journal of the Science of Food and Agriculture 29, 979-988.

Theander O \& Åman P (1979) Studies on dietary fibres. I. Analysis and chemical characterization of water-soluble and water- insoluble dietary fibres. Swedish Journal of Agricultural Research 9, 97-106.

Theander O, Aman P, Westerlund E \& Graham H (1990) The Uppsala method for rapid analysis of total dietary fiber. In New Developments in Dietary Fiber, pp. 273-281 [I Furda and CJ Brine, editors]. New York: Plenum Press.

Thomas B (1972) Beiträge zur Nomenklatur und Analytik pflanzlicher Zellwandsubstanzen. Getreide, Mehl und Brot 26, 158-165, 168-169.

Van Soest P (1963a) Use of detergents in the analysis of fibrous feeds. I. Preparation of fiber residues of low nitrogen content. Journal of the Official Agricultural Chemists 46, 825-829.

Van Soest P (1963b) Use of detergents in the analysis of fibrous feeds. II. A rapid method for the determination of fiber and lignin. Journal of the Official Agricultural Chemists 46, 829-835.

Van Soest P \& Wine RH (1967) Use of detergents in the analysis of fibrous feeds. IV. Determination of plant cell wall constituents. Journal of the Official Agricultural Chemists 50, 50-55.

Widdowson EM \& McCance RA (1935) The available carbohydrates of fruits. Determination of glucose, fructose, sucrose, and starch. Biochemical Journal 29, 151-156.

Williams RD \& Olmstedt W (1935) A biochemical method for determining indigestible residue (crude fibre) in faeces: lignin, cellulose, and non-water soluble hemicelluloses. Journal of Biological Chemistry 108, 653-666. 